\title{
An experimental study to assess the best maneuver when using a reverse side-bevel histology needle for EUS-guided fine-needle biopsy
}

Authors

Institution
Akane Yamabe, Atsushi Irisawa, Goro Shibukawa, Koki Hoshi, Mariko Fujisawa, Ryo Igarashi, Yoko Abe, Koh Imbe

Department of Gastroenterology, Fukushima Medical University Aizu Medical Center

\section{Bibliography}

DOI http://dx.doi.org/

10.1055/s-0041-107801

Published online: 27.11.2015

Endoscopy International Open 2016; 04: E56-E61

(c) Georg Thieme Verlag KG

Stuttgart · New York

E-ISSN 2196-9736

\section{Corresponding author}

Atsushi Irisawa

Department of

Gastroenterology

Fukushima Medical University

Aizu Medical Center

Arzuwakamazu

Japan

irisawa@fmu.ac.jp
Background and study aims: Recently, ProCore ${ }^{\mathrm{TM}}$ was developed as an endoscopy ultrasound (EUS)-guided histology needle designed to address several current limitations of EUS-guided fine-needle aspiration (FNA). Nevertheless, tissue yield with the ProCore ${ }^{\mathrm{TM}}$ is not consistent. No standard technique has been established. This experimental study was conducted to ascertain the best maneuver when using the ProCore ${ }^{\mathrm{TM}}$.

Patients and methods: We performed fine-needle aspiration and biopsy (FNAB) with a 22-gauge (G) ProCore $^{\mathrm{TM}}$ using chicken tenderloin and liver. Six methods were used, with two needle movement techniques (natural speed and whipping back) and three negative pressures (no suction (NS), slow pull (SP), and 10-mL suction).

Results: In cases using the "natural speed" technique, a significant difference in tissue yield was found with suction pressures in both tenderloin and liver $(P<0.0001, P=0.0079)$. In cases using

\section{Introduction}

$\nabla$

Endoscopic ultrasound (EUS)-guided fine-needle aspiration (FNA) is efficacious for sampling solid mass lesions. The technique of EUS-FNA has spread rapidly, finding wide use as a less-invasive, reliable, and safe technique for obtaining tissue specimens from pancreatic tumors, lymphadenopathy, and gastrointestinal subepithelial and other lesions. Its diagnostic yield, however, could be improved as past studies have shown it to be around $90 \%$ [1-4].

To achieve adequate tissue sampling, various EUSFNA needle devices have been developed. Recently, a needle (Echo Tip ${ }^{\circledR}$ HD ProCore ${ }^{\mathrm{TM}}$; WilsonCook Medical Inc., Winston-Salem, NC) that combines the attributes of both FNA and fine-needle biopsy (FNB) has been introduced and rapidly achieved wide usage [5]. The device has a reverse bevel side fenestration that allows tissue to be suctioned into the bevel, yielding a core of tissue the "whipping back" technique, for the tenderloin, no significant difference in tissue yield was found for NS vs. SP $(P=0.0596)$, however, a significant difference was found for SP vs. $10-\mathrm{mL}$ suction $(P<0.0001)$ and for NS vs. $10-\mathrm{mL}$ suction $(P<0.0001)$. For the liver, a significant difference was found among suction pressures $(P=0.0079)$. Comparing "natural speed" with "whipping back" using the tenderloin, no significant difference in tissue yield was found with NS and $10 \mathrm{~mL}$ of pressure $(P=0.1126, P=0.0718)$, but a significant difference was found with SP $(P=0.0028)$. Regarding the liver, no significant difference was found based upon suction pressure (NS $P=$ 0.1508; SP $P=0.0873 ; 10 \mathrm{~mL} P=0.6667$ ).

Conclusions: EUS-FNAB using ProCore ${ }^{\mathrm{TM}}$ can be performed with negative pressure with any needling technique. Although ProCore ${ }^{\mathrm{TM}}$ has a reverse side-bevel, results in using it with a whippingback technique were inconclusive.

upon withdrawal ( $\mathbf{F i g . 1}$ ). The theoretical advantages of ProCore ${ }^{\mathrm{TM}}$ include: 1) a "core trap" within the needle, which holds the core specimen; 2) a "reverse side-bevel," which serves to cut the specimen and allows tissue to be scraped into the bevel so that core tissue can be obtained upon device withdrawal. Procore ${ }^{\mathrm{TM}}$ was developed as a biopsy needle that can absorb material, which clearly distinguishes it from a core cut needle.

A study of EUS-FNA and biopsy (FNAB) using the ProCore ${ }^{\mathrm{TM}}$ needle has shown an increase in diagnostic accuracy of approximately $15 \%$ compared to EUS-FNA conducted with a standard needle [6]. However, a recent study demonstrated that the diagnostic sufficiency and technical performance of a standard FNA needle and the FNAB needle (ProCore ${ }^{\mathrm{TM}}$ ) are comparable. No significant difference was found between the two needle types in the yield or quality of the histologic core [7]. However, the evaluation of the FNAB needle is 
not clear. The tissue yield with the ProCore ${ }^{\mathrm{TM}}$ is not regarded as consistent because no standard FNAB technique has been established.

Because of the unique characteristics of the ProCore ${ }^{\mathrm{TM}}$ needle, we theorized that moving it with a whipping back technique might yield more tissue than moving it at natural speed because the needle has a "reverse side-bevel" that cuts the specimen. It also was unclear whether application of suction pressure would be beneficial when using ProCore ${ }^{\mathrm{TM}}$. A slow-pull technique, whereby simultaneous minimal negative pressure is provided by pulling the stylet slowly and continuously, has been reported to be useful for EUS-FNAB $[8,9]$, but its value remains controversial. Therefore, we conducted an experiment to ascertain which maneuver was better for EUS-FNAB using the ProCore ${ }^{\mathrm{TM}}$ needle. This study was undertaken to ascertain the best movements for using the ProCore $^{\mathrm{TM}}$ in EUS-FNAB.

\section{Materials and methods}

$\nabla$

Two endoscopists (AY and AI) alternated performance of FNAB on fresh chicken tenderloin and liver using 22-gauge (G) ProCore ${ }^{\mathrm{TM}}$ needles without using an endoscope. To effectively use the "reverse side-bevel" that characterizes ProCore ${ }^{\mathrm{TM}}$, movement of the needle with a whipping back technique might be important. Therefore, the following two methods were evaluated: the "whipping back" technique and the conventional method using "natural speed." To perform whipping back of the needle, we constructed a handmade device with a stopper attached to the top ( $\bullet$ Fig. 2). When the needle is pulled vigorously, it stops at a constant distance. Furthermore, the hole in the top of the device enables penetration of the extension tube. When the needle is pushed forward using the whipping back technique, the puncture speed was natural. The length of punctures in the chicken tenderloin and the liver were uniform $(20 \mathrm{~mm}) ; 10$ passes were made for each puncture.

As in previous reports, three types of suction pressures were used: "without suction" [10], "with slow pull technique" [9], and "with $10-\mathrm{mL}$ suction force" [11]. We standardized our techniques for core biopsy as follows. Six techniques with 10 back-and-forth movements of the needle per pass were evaluated: 1) needling with "natural speed" without suction; 2) needling with "natural speed" with slow-pull technique; 3) needling with "natural speed" with 10-mL suction; 4) needling with "whipping back" without suction; 5) needling with "whipping back" with the slow-pull technique; and 6) needling with "whipping back" with 10 -mL suction. After FNAB, the tissues obtained were expressed entirely onto a chart by reinsertion of the stylet. In most cases, tissue was obtained from the needlepoint and reverse side-bevel. The materials were evaluated based on whether a visible core for histology was obtained. An electronic balance was used to weight the specimens and differences in weight for materials obtained with the "whipping back" technique and the conventional method with "natural speed" were assessed. In addition, the effect of suction was assessed by examining the difference in the weight of tissue obtained "without suction," "with slow pull technique," and "with 10-mL suction" for each technique.

The differences in the weights of obtained materials between two groups were analyzed using the Mann-Whitney U test. Confidence interval $(95 \% \mathrm{CI})$ was calculated for differences in proportions for categorical data, and the approximate $95 \%$ confidence interval $(\mathrm{CI})$ for differences in medians for nonparametric data

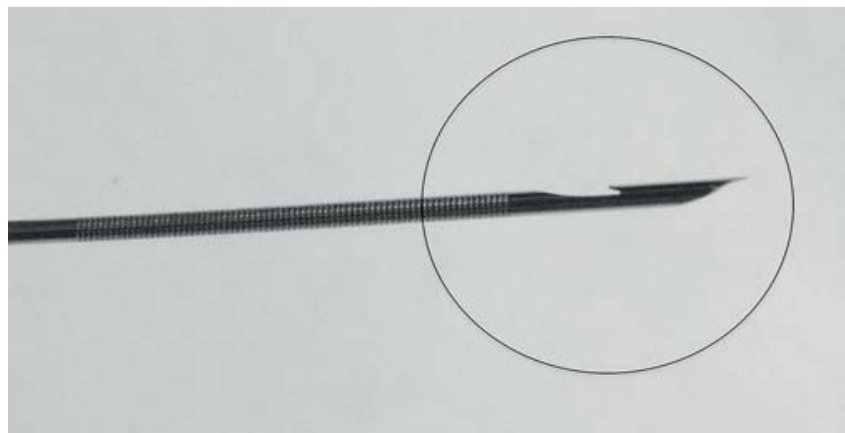

Fig. 1 A new core biopsy needle demonstrating the hollowed-out "reverse side-bevel" (circle), which serves to cut the specimen.

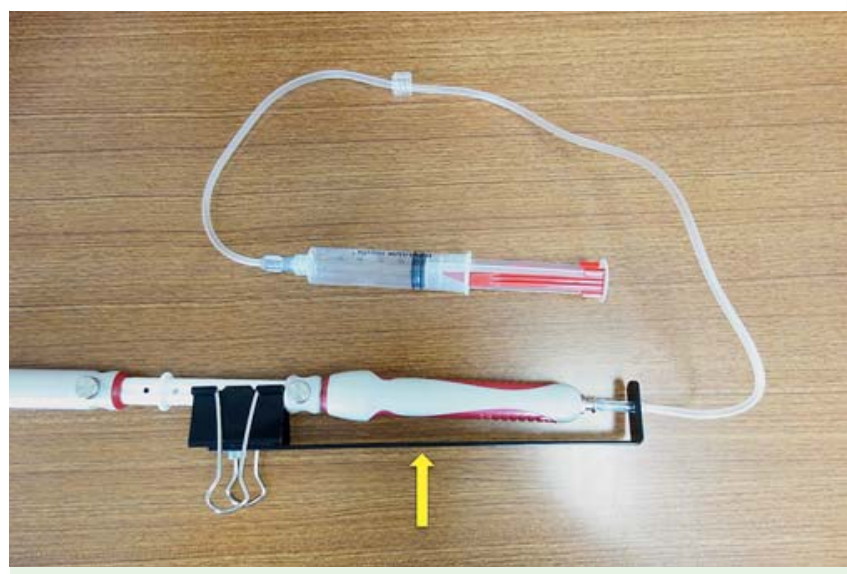

Fig. 2 Handmade device that attaches the stopper (arrow) for the "whipping back" technique.

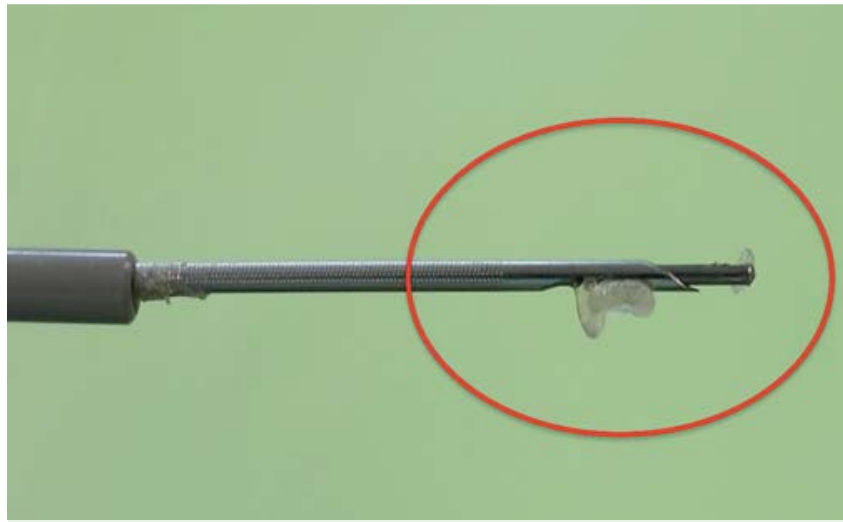

Fig. 3 The tissue obtained was entirely expressed onto a chart by reinserting the stylet and the total weight was measured by electronic balance.

was calculated. All data analyses were performed using GraphPad Prism 6 (GraphPad Software Inc., La Jolla, CA, USA). All $P$ values were two-sided, and statistical significance was set at $P<0.05$.

\section{Results \\ $\nabla$}

For each tissue type and for all techniques, more specimens were obtained with higher negative pressure. Moreover, visible core samples ( Fig.3) were obtained consistently in the groups with negative pressure. 

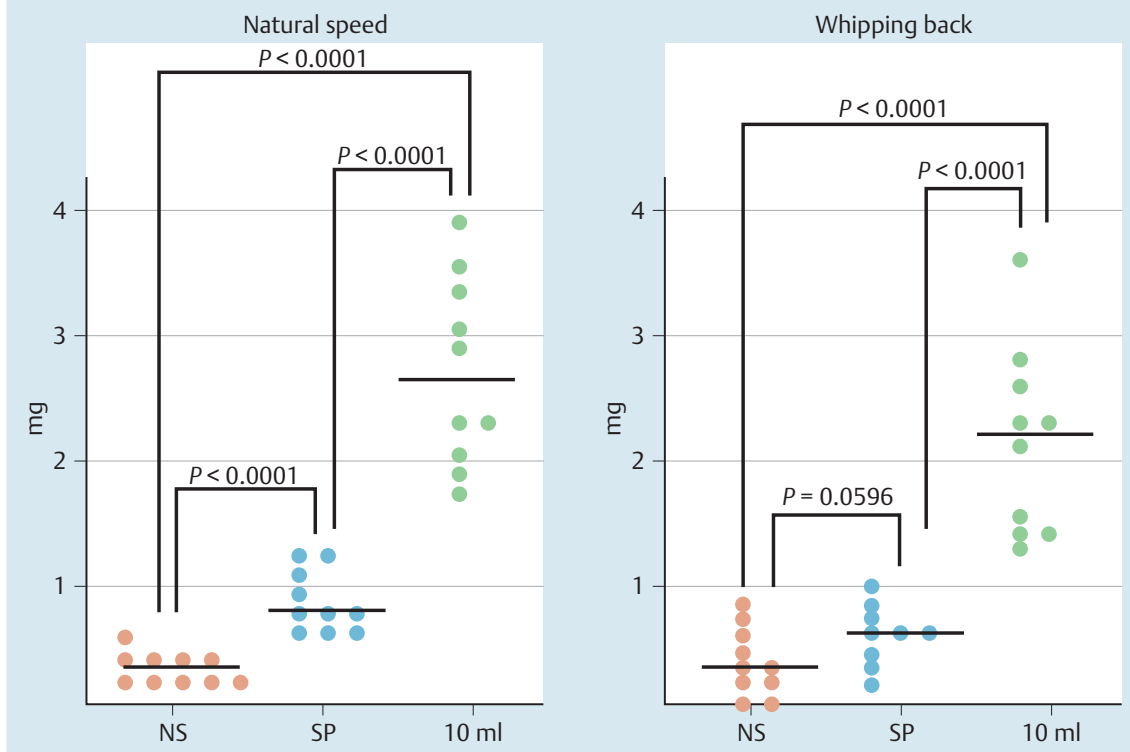

Fig. 4 Weights of tissue obtained from the chicken tenderloin using the "natural speed" and the "whipping back" techniques were measured at each suction pressure.
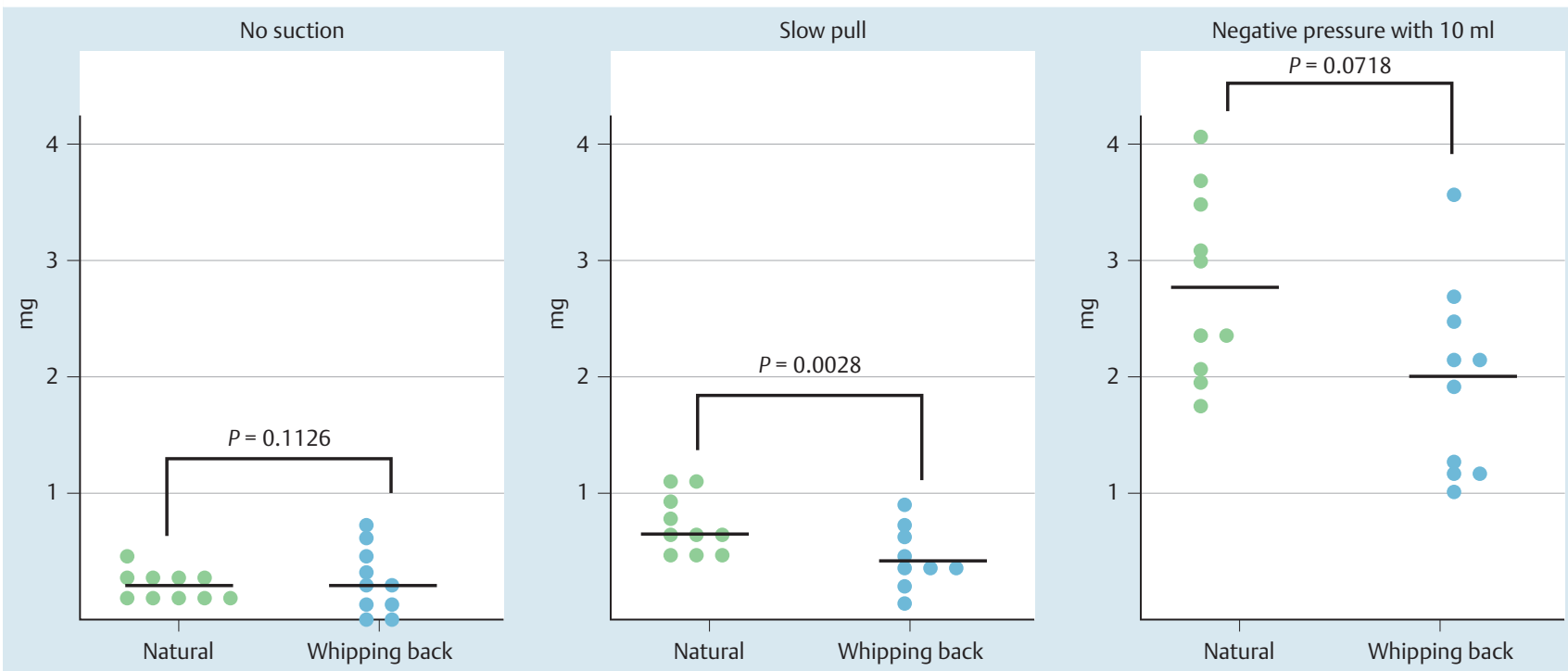

Fig. 5 Weights of tissue obtained from the chicken tenderloin using various suction pressures were measured for each needling technique.

\section{FNAB for chicken tenderloin}

Cases using "natural speed" technique

The weights of obtained tissues averaged $0.35 \mathrm{mg}$ (median) [range, $0.3 \sim 0.5 \mathrm{mg}$ ] in the no-suction group, $0.7 \mathrm{mg}$ [range, $0.6 \sim 1.1 \mathrm{mg}$ ] in the slow-pull group, and $2.45 \mathrm{mg}$ [range, $1.8 \sim 3.8 \mathrm{mg}$ ] in the $10-\mathrm{mL}$ suction group ( $\bullet$ Fig.4). Significant differences were found between different suction pressures (no-suction vs. slow-pull; 95\% CI, 0.3000 0.6000; $P<0.0001$, slow-pull vs. $10-\mathrm{mL}$ suction; $95 \%$ $\mathrm{CI}, 1.200 \sim 2.400 ; P<0.0001$, no-suction vs. $10-\mathrm{mL}$ suction; $95 \% \mathrm{CI}$, $1.600 \sim 2.800 ; P<0.0001)$.

\section{Cases using "whipping back" technique}

The weights of obtained tissues averaged $0.2 \mathrm{mg}$ [range, $0 \sim 0.6 \mathrm{mg}$ ] in the no-suction group, $0.4 \mathrm{mg}$ [range, $0.1 \sim 0.8 \mathrm{mg}$ ] in the slowpull group, and $2.0 \mathrm{mg}$ [range, $1.2 \sim 3.4 \mathrm{mg}$ ] in the $10-\mathrm{mL}$ suction group ( $\bullet$ Fig.4).

No significant difference was found between the no-suction and the slow-pull groups (95\%CI, 0. 0 0.4000; $P=0.0596$ ), but a significant difference was found between slow-pull and $10-\mathrm{mL}$ suc- tion (95\%CI, 0. 9000 2.000; $P<0.0001$ ), and between no-suction and 10 -mL suction (95\%CI, $1.100 \sim 2,200 ; P<0.0001)$.

\section{Comparison between needling methods with the same} suction pressure

Comparison of "Natural speed" with "Whipping back" techniques using the same suction pressure showed no significant difference at no-suction and $10-\mathrm{mL}$ suction (no-suction; $95 \% \mathrm{CI},-0.1000$ 0.3000; $P=0.1126,10-\mathrm{mL}$ suction; $95 \% \mathrm{CI},-0.1000 \sim 1.4000 ; P=$ 0.0718 ), but a significant difference at slow pull (95\%Cl, $0.1000 \sim$ $0.5000 ; P=0.0028$ ), as shown in $\bullet$ Fig.5.

\section{FNAB for chicken liver}

Cases using "natural speed" technique

The weights of obtained tissues averaged $0.8 \mathrm{mg}$ [range, $0.3-$ $2.7 \mathrm{mg}$ ] in the no-suction group, $4.6 \mathrm{mg}$ [range, $3.1-8.8 \mathrm{mg}$ ] in the slow-pull group, and $18.7 \mathrm{mg}$ [range, $13.6-25 \mathrm{mg}$ ] in the 10 -mL suction group ( $\bullet$ Fig. 6 ). 
Significant differences were found between different suction pressures (no-suction vs. slow-pull; 95\%CI,1.900 8.000; $P=$ 0.0079 , slow-pull vs. $10-\mathrm{mL}$ suction; 95\%CI, 8.700 20.40; $P=$ 0.0079 , no-suction vs. $10-\mathrm{mL}$ suction; $95 \% \mathrm{CI}, 12.80 \sim 24.20 ; P=$ 0.0079).

\section{Cases using "whipping back" technique}

The weights of obtained tissues averaged $2.1 \mathrm{mg}$ [range, 1.1 $3.3 \mathrm{mg}$ ] in the no-suction group, $7.5 \mathrm{mg}$ [range, $5.2-8.9 \mathrm{mg}$ ] in the slow-pull group, and $15.8 \mathrm{mg}$ [range, $13.2-22 \mathrm{mg}$ ] in the 10 -mL suction group ( $\bullet$ Fig. 6 ).

Significant differences were found between different suction pressures (no-suction vs. slow-pull; 95\%CI, 3.100 6.800; $P=$ 0.0079 , slow-pull vs. 10 -mL suction; 95\%CI, 5.500 14.50; $P=$ 0.0079 , no-suction vs. $10-\mathrm{mL}$ suction; $95 \% \mathrm{CI}, 0.90 \sim 19.90 ; P=$ $0.0079)$.

\section{Comparison of needling methods using the same suction pressure}

Comparison between "natural speed" and "whipping back" using the same suction pressure showed no significant differences at any suction pressure (no-suction; 95\%CI, $-2.5000 \sim 0.6000 ; P=$ 0.1508 , slow pull; $95 \% \mathrm{CI},-4.400 \sim 1.300 ; P=0.0873,10 \mathrm{ml}$ suction; 95\%Cl, $-6.0000 ~ 9.2000 ; P=0.6667$ ), as shown in $\bullet$ Fig. 7.

\section{Discussion}

$\nabla$

EUS-FNA is a highly accurate method of obtaining tissue to diagnose various diseases. Cytology of samples obtained with FNA is generally adequate for diagnosis of malignancy, but histologic examination may be necessary for tumors such as lymphoma, gastrointestinal stromal tumor (GIST), and metastatic carcinoma. In addition, pathologists may specifically request core tissue to establish a definitive diagnosis in challenging cases [12,13]. An FNB specimen includes core tissue with better preservation of cellular architecture than an aspirate [14]. In general, use of an FNB specimen achieves greater diagnostic accuracy and the technique provides more tissue for ancillary testing than does an FNA sample [15]. EUS-guided trucut needle biopsy (EUS-TNB; Cook Endoscopy Inc., Winston-Salem, NC, USA) was used to overcome the limitations of EUS- FNA by acquisition of histology specimens to support evaluation of tissue architecture and the use of immunohistochemistry. The overall diagnostic accuracy of EUS-TNB for evaluating suspicious lesions at various sites in the body is reportedly $75 \%$ to $84 \%$ and $61 \%$ to $67.5 \%$ for pancreatic masses $[16,17]$. Although the EUS-TNB technique exhibits some advantages over FNA, criticisms of EUS-TNB include difficult maneuverability because of needle rigidity and its spring-loaded mechanism, increased cost, uncertain safety, and a paucity of clinical data to develop practice guidelines [18].

"EUS-guided ProCore ${ }^{\mathrm{TM}}$ biopsy" recently was introduced, combining the attributes of both FNA and FNB and a new design of core needles incorporating a hollowed-out reverse bevel to trap core specimens [5]. The device has a 2-mm reverse bevel side fenestration $3.9 \mathrm{~mm}$ from the needle tip, which enables suctioning of tissue into the bevel and acquisition of core tissue on withdrawal. ProCore ${ }^{\mathrm{TM}}$ has three needle sizes (19-G, 22-G, 25-G), and when tight angulation of the echoendoscope or the use of a forceps elevator is necessary, the $22-\mathrm{G}$ or $25-\mathrm{G}$ needles appear to be suitable for insertion. Iglesias-Garcia et al reported that the technique of EUS-FNAB with ProCore ${ }^{\mathrm{TM}} 19 \mathrm{G}$ is feasible and safe for histopathologic diagnosis. The sample quality, according to the pathologist, was adequate for full histologic assessment in $85.9 \%$ of lesions (98 of 114) [5].

To obtain better samples (especially for histology), various suction techniques using ProCore ${ }^{\mathrm{TM}}$ have been explored. Nakai et al reported the usefulness of the slow-pull technique, which provides less bloody specimens without reducing cellularity in EUSFNA for pancreatic malignant lesions. Moreover, the sensitivity of the slow-pull technique is similar in terms of cytology but higher than that for histology [9]. In another report, Bang et al described the possibility of obtaining tissue for cytologic analysis in $89.3 \%$ and histologic analysis in $83.3 \%$ of cases using the 22-G ProCore $^{\mathrm{TM}}$ with $10 \mathrm{~mL}$ suction [10]. In addition, Fabbri et al reported that the overall sensitivity, specificity, and accuracy of EUS-FNB using a 22-G ProCore ${ }^{\mathrm{TM}}$ in solid pancreatic lesions of $\leq 2 \mathrm{~cm}$ with $10 \mathrm{~mL}$ suction pressure were $80 \%, 100 \%$, and $82 \%$, respectively [19]. Witt et a. described that $73 \%$ of cases had corresponding cell blocks and contained representative diagnostic material using ProCore ${ }^{\mathrm{TM}}$ with or without suction [20]. Strand et al. demonstrated that EUS-FNB using suction with strength entrusted to the discretion of the acting endoscopist was successful in $84.4 \%$ of cases, and that core tissue for histologic examination could be obtained in $70.3 \%$ of cases [21]. As described above, the standard method of suction for ProCore ${ }^{\mathrm{TM}}$ remains controversial and data on it are inconclusive.

Past reports from relevant literature suggest that use of a ProCore $^{\mathrm{TM}}$ needle with conventional EUS-FNA technique provides high tissue yields. Although the needle movement is done at natural speed or rapidly at the moment of needling with conventional EUS-FNA technique [22], controversy exists about which needling technique is best for obtaining samples for histology. Given the characteristics of the ProCore ${ }^{\mathrm{TM}}$ needle, moving it with a whipping back technique might produce more tissue than doing so at a natural speed because it has a "reverse sidebevel," that serves to cut the specimen. In addition, the suction best suited for ProCore ${ }^{\mathrm{TM}}$ use remains undetermined. Therefore, we assessed how much material could be obtained using two needling techniques and three suction techniques. In our experimental study, the unique structure of ProCore ${ }^{\mathrm{TM}}$ did not necessitate a particular needling method. With regard to the suction technique, higher negative pressure yielded more specimen from both tissue targets (chicken tenderloin and liver) regardless of movement technique.

Several reports have described the usefulness of the slow-pull technique for obtaining good-quality samples when using a ProCore $^{\mathrm{TM}}$ needle [9]. Katanuma et al. showed that the slow-pull technique offers fundamentally no suction in their bench-top testing, and questioned its usefulness [23]. In our experimental data, the quantities of tissues obtained were much greater in the slow-pull group than in the no-suction group. This result shows that the slow-pull technique has some absorption effect when obtaining tissues from a solid mass. In addition, the capillary pressure might affect the results described. The quality of samples is regarded as an advantage of the slow-pull technique, but for this study, we are unable to provide insight on that because we did not evaluate our specimens under a microscope. However, because obtaining more tissue for histopathologic diagnosis is extremely important, reliable absorption appears to be necessary, even with use of a ProCore ${ }^{\mathrm{TM}}$ needle.

For this study, we used fresh chicken liver and were conscious of the potential for blood contamination because fresh liver includes blood. Macroscopic observation of all specimens obtained 

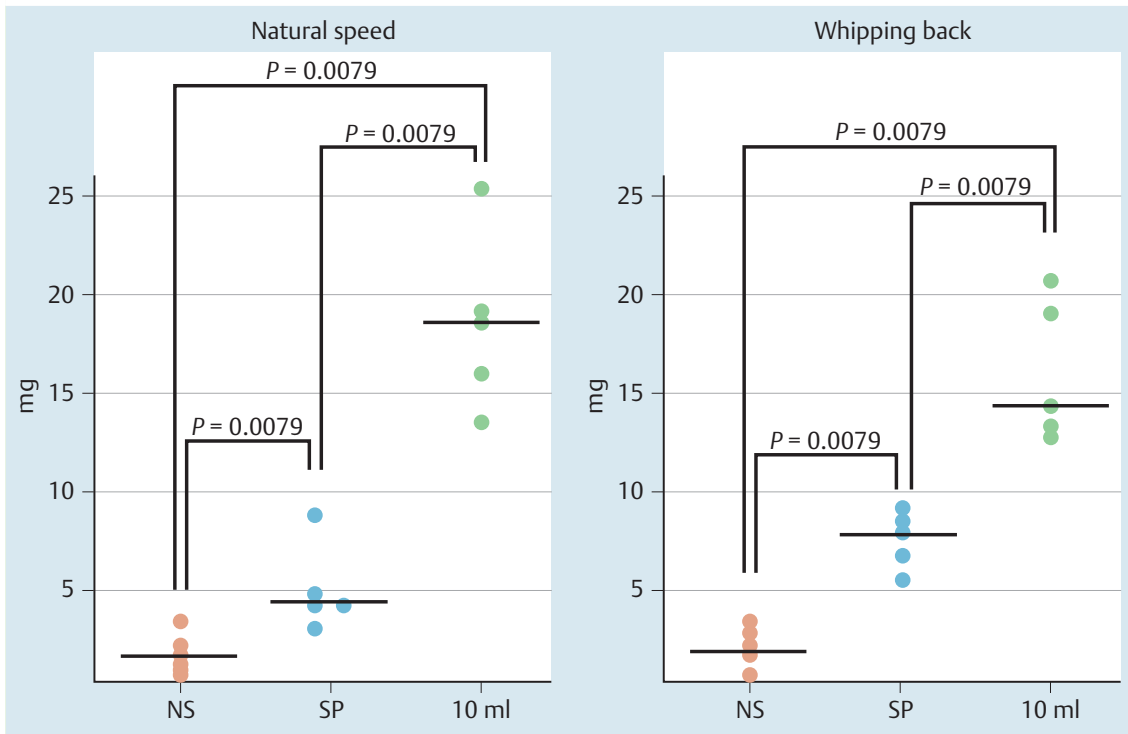

Fig. 6 Weights of tissue obtained from the chicken liver using the "natural speed" and "whipping back" techniques were measured at each suction pressure.
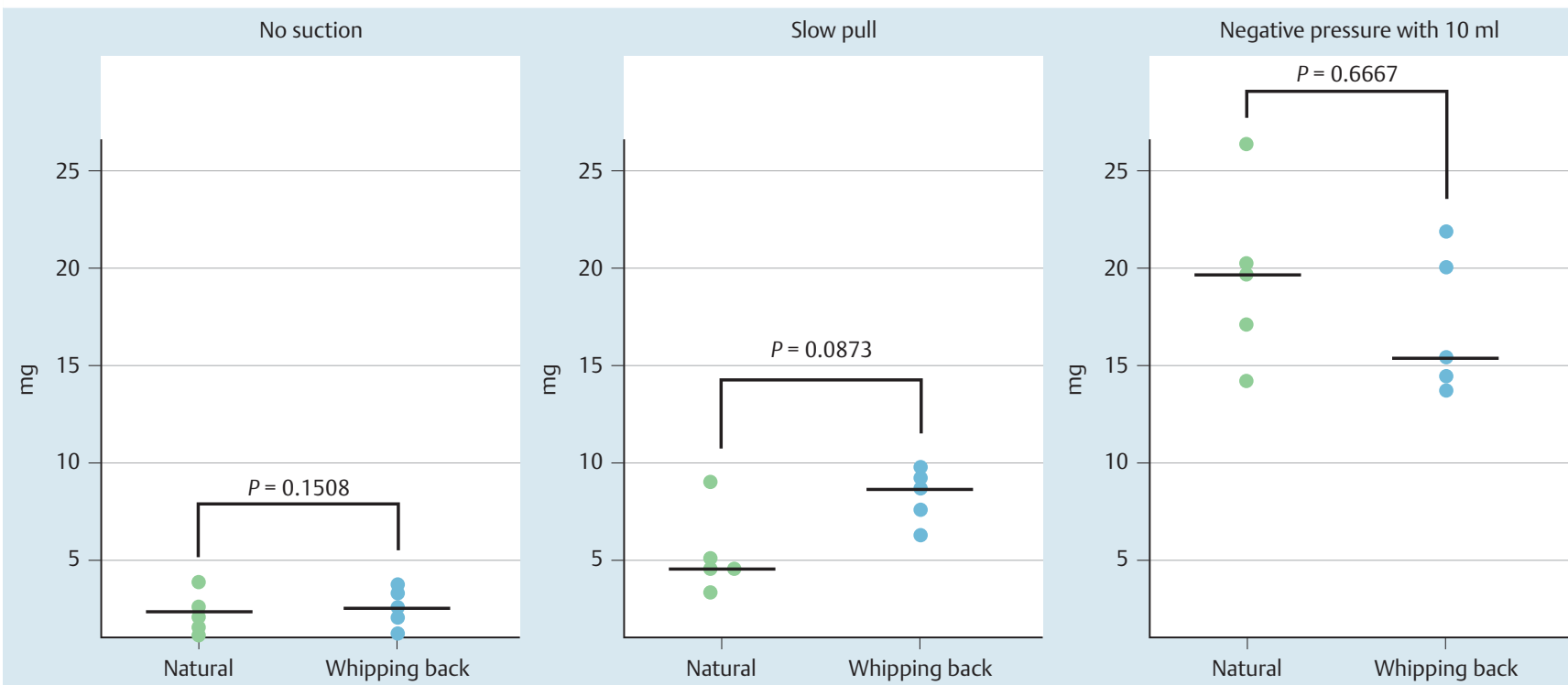

Fig.7 Weights of tissue obtained from the chicken liver using various suction pressure were measured for each needling technique.

during our procedures showed little or no adhesion of blood. Although we did not perform microscopic evaluation of sample quality, the presence of blood did not obstruct sampling of an adequate or large amount of tissue with any technique. Nevertheless, an important limitation of our experimental study is that the fresh chicken tenderloin and liver that we used were not live organs. From a clinical perspective, results with the techniques might differ depending on the quantity of blood in the target and differences in tissues subject to sampling. A prospective, randomized, controlled trial must be conducted using live organs or tumors to ascertain the optimal technique for use of ProCore ${ }^{\mathrm{TM}}$ in EUS-guided biopsy.

In conclusion, results of our experimental study indicate that EUS-FNAB using ProCore ${ }^{\mathrm{TM}}$ might be performed best with negative pressure (at least $10 \mathrm{~mL}$ ) in any needling technique or those using other FNA needles. Although ProCore ${ }^{\mathrm{TM}}$ has a reverse sidebevel, it does not appear that the "whipping back" technique would be useful. In addition, no blood vessels were seen in the target materials, a fact that makes it difficult to draw clear con- clusions about the effects and usefulness of the slow-pull technique.

\section{Competing interests: None}

\section{References}

1 Wiersema MJ, Vilmann P, Giovannini M et al. Endosonography-guided fine-needle aspiration biopsy: diagnostic accuracy and complication assessment. Gastroenterology 1997; 112: 1087-1095

2 Siddiqui UD, Rossi F, Rosenthal LS et al. EUS-guided FNA of solid pancreatic masses: a prospective, randomized trial comparing 22-gauge and 25-gauge needles. Gastrointest Endosc 2009; 70: 1093-1097

3 Nguyen TT, Lee CE, Whang CS et al. A Comparison of the diagnostic yield and specimen adequacy between 22 and 25 gauge needles for endoscopic ultrasound guided fine-needle aspiration (EUS-FNA) of solid pancreatic lesions (SPL): is larger better? Gastrointest Endosc 2008; 67: AB100

4 Wakatsuki T, Irisawa A, Bhutani MS et al. Comparative study of diagnostic value of cytologic sampling by endoscopic ultrasonographyguided fine-needle aspiration and that by endoscopic retrograde pancreatography for the management of pancreatic mass without biliary stricture. J Gastroenterol Hepatol 2005; 20: 1707-1711 
5 Iglesias-Garcia J, Poley JW, Larghi A et al. Feasibility and yield of a new EUS histology needle: results from a multicenter, pooled, cohort study. Gastrointest Endosc 2011; 73: 1189-1196

6 Iglesias-Garcia J, Abdulkader I, Souto R et al. Procore histology needles (19-gauge and 22 gauge) vs. standard cytology needles (22-gauge and 25 -gauge) in the differential diagnosis of solid pancreatic tumors. Gastrointest Endosc 2011; 73: AB248

7 Bang JY, Hebert-Magee S, Trevino J et al. Randomized trial comparing the 22-gauge aspiration and 22-gauge biopsy needles for EUS-guided sampling of solid pancreatic mass lesions. Gastrointest Endosc 2012; 76: $321-327$

8 Iwashita T, Nakai Y, Samarasena JB et al. High single-pass diagnostic yield (cytology and histology) of a novel 25-gauge core biopsy needle for endoscopic ultrasound-guided fine needle aspiration and biopsy (EUS-FNAB) in pancreatic solid lesions. Gastrointest Endosc 2013; 77: 909-915

9 Nakai $Y$, Isayama $H$, Yamamoto $N$ et al. A comparative study of suction technique vs. slow pull technique in EUS-FNA for pancreatic malignant lesions. Gastrointest Endosc 2014; 59: 1578 - 1585

10 Bang JY, Hebert-Magee S, Trevino J et al. Randomized trial comparing the 22-gauge aspiration and 22-gauge biopsy needles for EUS-guided sampling of solid pancreatic mass lesions. Gastrointest Endosc 2012; 76: $321-327$

11 Bhutani MS, Suryaprasad S, Moezzi J et al. Improved technique for performing endoscopic ultrasound guided fine needle aspiration of lymph nodes. Endoscopy 1999; 31: 550-553

12 Varadarajulu S, Fraig M, Schmulewitz $N$ et al. Comparison of EUS-guided 19-gauge Trucut needle biopsy with EUS-guided fine-needle aspiration. Endoscopy 2004; 36: 397-401
13 Levy MJ, Reddy RP, Wiersema MJ et al. EUS-guided trucut biopsy in establishing autoimmune pancreatitis as the cause of obstructive jaundice. Gastrointest Endosc 2005; 61: 467-472

14 Yang YJ, Damron TA. Comparison of needle core biopsy and fine-needle aspiration for diagnostic accuracy in musculoskeletal lesions. Arch Pathol Lab Med 2004; 128: 759-764

15 Varadarajulu S, Hasan MK, Bang JY et al. Endoscopic ultrasound-guided tissue acquisition. Dig Endosc 2014; 26: $62-69$

16 Thomas T, Kaye PV, Ragunath Ket al. Efficacy, safety, and predictive factors for a positive yield of EUS-guided Trucut biopsy: a large tertiary referral center experience. Am J Gastroenterol 2009; 104: 584 - 591

17 Larghi A, Verna EC, Stavropoulos SN et al. EUS-guided trucut needle biopsies in patients with solid pancreatic masses: a prospective study. Gastrointest Endosc 2004; 59: 185-190

18 Cho CM, Al-Haddad M, Leblanc JK et al. Rescue endoscopic ultrasound (EUS)-guided trucut biopsy following suboptimal EUS-guided fine needle aspiration for mediastinal lesions. Gut Liver 2013; 7: 150-156

19 Fabbri C, Luigiano C, Maimone A et al. Endoscopic ultrasound-guided fine-needle biopsy of small solid pancreatic lesions using a 22-gauge needle with side fenestration. Surg Endosc 2015; 29: 1586-1590

20 Witt BL, Adler DG, Hilden K et al. A comparative needle study: EUS-FNA procedures using the HD ProCore(TM and EchoTipTM)22-gauge needle types. Diagn Cytopathol 2013; 41: 1069-1074

21 Strand DS, Jeffus SK, Sauer BG et al. EUS-guided 22-gauge fine-needle aspiration versus core biopsy needle in the evaluation of solid pancreatic neoplasms. Diagn Cytopathol 2014; 42: 751 -758

22 Irisawa A, Hikichi T, Bhutani MS et al. Basic technique of FNA. Gastrointest Endosc 2009; 69: 125-129

23 Katanuma A, Itoi T, Baron TH et al. Bench-top testing of suction forces generated through endoscopic ultrasound-guided aspiration needles. J Hepatobiliary Pancreat Sci 2015; 22: 379-385 